education of his children. From 1769 onwards, these instruments were housed at the King's private observatory at Richmond, Surrey, a building now known as Kew Observatory. In 1841 they were presented to King's College, London, where they remained until they were transferred on loan to the Science Museum, London, S.W.7, in 1926. The collection has been on view to the public on only two previous occasions, namely, for short periods in 1928 and 1949 , and the recent completion of the first stage of the rebuilding plan for the Science Museum now makes it possible for approximately one-half of this collection to be placed on permanent exhibition in one of the reconstructed galleries. The instruments, the majority of which were acquired between 1740 and 1768 , cover the field of study known, in the eighteenth century, by the title of 'experimental philosophy'; although the collection is particularly rich in material designed for experiments in mechanies, pneumatics and electricity, numerous examples are also included of instruments used in astronomy, optics, surveying, magnetism, acoustics, chemistry and heat. The collection thus affords not only a valuable display of the type of science being taught during an important era in scientific development, but it also provides a fine example of the skill and craftsmanship of the scientific instrument maker of the period. A descriptive catalogue of the complete collection is now available from the Science Museum (price $7 s .6 d$.), and there is also a guide book (price $6 d$.) which gives a brief outline of the history of the collection, together with notes about some of the more important scientific instruments represented in the exhibition.

\section{Bibliography of Geiger-Müller Counters}

A SHORT but useful bibliography of articles that have appeared during 1931-50, inclusive, on GeigerMüller photon counters has been compiled by J. E. Walker, of the Electronics Division of the United States National Bureau of Standards (Report 1050; pp. 16 ; Washington, D.C. : Nat. Bur. Stand., 1952) Eighty-one papers or books, arranged in alphabetical order of authors, are listed. Most of the papers in English and German have been included, but only a selection of those in French, Russian and Italian; and it is a pity that no attempt was made to make the bibliography complete. Each reference is followed by either the author's abstract or comments by Mr. Walker. Those of historical interest only are dealt with very briefly.

\section{Oil Exhibition at the City Museum, Bristol}

A scientific and technical oil exhibition, designed expressly for a museum public, is now on view in the City Museum, Bristol, until May 2, prior to touring other provincial museums. Developed by the Shell Petroleum Co., Ltd., the exhibition aims both at attracting and educating, and is readily understandable without the need for accompanying lectures or explanatory talks. Starting with the origin of oil, the exhibition goes on to deal with exploration, drilling and the development of oil fields and with the different means of transport; the chain of events from refining, manufacture and research to the distribution of products to consumers is also outlined. The whole arrangement is made up of twenty-two portable display cases, one or more of which are devoted to each of the fifteen subjects into which the activities of the industry have been divided. The treatment of the displays differs : some include models, reliefs or dioramas ; others are purely photographic, with pictures of artistic merit as well as of technical interest. Each display is labelled, and there is a descriptive leaflet available to visitors.

\section{Flora and Fauna of South Carolina}

THE first number of University of South Carolina Publications: Series 3, Biology, has recently been published $(1$, No. 1 ; pp. 41 ; 1952 ; from the University, Columbia, S.C.; 75 cents). This is a new journal that is to be devoted to taxonomic studies of the flora and fauna of the State of South Carolina. It is published by the Research Committee of the University at irregular intervals as the material is available, and the first number consists of two contributions, the first of which, by J. T. Penny, is on the amphibians and reptiles of the State. Of the amphibians, fiftyfive species with eleven sub-species are listed and, of the reptiles, fifty-nine species and fifteen sub-species, which gives an idea of the richness of this fauna in South Carolina. In each instance the type locality of the form is given. The second paper, by Harry W. Freeman, on the "Fishes of Richland County", is based upon a collection from thirty-seven localities, all listed, and reports forty-nine species and one specimen considered as a hybrid. Up to the time of this collection only eighteen species had been recorded, and the author obtained thirteen of these, so that the total number of species recorded from the county is fifty-four. Both papers start with a short historical introduction, a point to be commended; the first reptile to be recorded was the alligator in 1682, but the first serious beginning was Catesby's elassical "Natural History of Carolina, Florida and Bahama Islands" (1730-48). Both papers also conclude with a complete bibliography. The printing, paper and layout are very satisfactory.

First International Polarographic Congress, Prague

THE third volume of the proceedings of the First International Polarographic Congress, held in Prague during February 1951, has now been published (pp. 774 ; from Orbis-Export, 30 Ve Smeckach, Prague II ; 10.80 dollars). The volume contains eight reports on the field of modern polarography, including its applications in chemical analysis, biochemistry and medicine, and these are followed by fifty-six contributions to the Congress, with discussions. The text is in Czech, with versions in Russian and extensively in English and German. This adds considerably to the bulk of the volume, but will be appreciated by readers not familiar with the first two languages. The volume is impressive as showing the great advances made in the important subject of polarography, and should be found of considerable interest.

\section{Second International Congress on Rheology, Oxford}

THE detailed programme of the Second International Congress on Rheology (see Nature, 170, 487; 1952), to be held in Oxford during July 26-31, has now been published. The address by the president of the Congress, Sir Geoffrey Taylor, will be on "Rheology for Mathematicians", and other general lectures will be given as follows : on the electroviscous effect (in French), by Mme. A. Dobry Duclaux (Paris); rheological problems in the fabrication of plastics, by R. S. Spencer (Midland, Mich.) ; rheology and applied mechanics, by R. N. J. Saal (Amsterdam); rheological behaviour and the molecular jumping mechanism, by F. H. Müller (Marburg); water association and hydrogels, by E. Forslind (Stock- 